\title{
Return Levels Approach and Periods of Currency Crises
}

\author{
Mouridi M. HAMIDOU ${ }^{1}$, Joseph K. Mung' atu $^{2} \&$ George O. Orwa ${ }^{3}$ \\ ${ }^{1}$ Pan African University, Institute for Basic Sciences, Technology and Innovation(PAUSTI), Department of Mathematics \\ (Statistics), Kenya \\ 2 Jomo-Kenyatta University of Agriculture and Technology (JKUAT), Department of Statistics and Actuarial Science, \\ Kenya \\ ${ }^{3}$ Jomo-Kenyatta University of Agriculture and Technology (JKUAT), Dean, School of Mathematical science, Kenya \\ Correspondence: Mouridi Mhoussini HAMIDOU, Pan African University, Institute for Basic Sciences, Technology and \\ Innovation(PAUSTI), Department of Mathematics (Statistics), Nairobi, Kenya. E-mail: mouridi1981@ outlook.com
}

Received: February 27, 2018 Accepted: March 15, 2018 Online Published: April 16, 2018

doi:10.5539/jmr.v10n3p77 URL: https://doi.org/10.5539/jmr.v10n3p77

\begin{abstract}
Dating and observing currency crisis periods lie at the heart of much international researchers. This is due to the lack of agreement in one research methodology. Until today, there does not exist a single theory or specific international policy regulation that can explain this phenomenon in global. To identify the periods of currency crisis, many methods have been brought out. Literature first employed a combination of sample mean and standard deviation. Some recent studies have attempted to use extreme value theory (EVT). Although these procedures have been more criticized in most of the literature. These drawbacks of existing approaches give rise to a new approach which is the main goal of this research. The main purpose of this study is to employ return levels technique to date currency crisis periods. The study will discuss only one method the block maxima approach. The stress losses i.e the generalized extreme value (GEV) distribution will be fitted to the annual block maxima to estimate the T-year return levels of extreme exchange market pressure index (EMPI). The parameters of the GEV distribution are estimated using the ML estimator method. Beside, a detailed procedure of the new approach is implemented. A comparison study between our identification approach and the existing conventional approach in the most literature is also conducted. We further illustrate the method by an empirical study on identifying periods of currency crisis of Kenya as case study. For practical implement the study focuses only on one single currency crisis model known as the alternative EMP index model for the intent of arbitrating the performance among various techniques. Results suggest that our new approach (RLDT) is performing better than the conventional method when the return period is considered big. Nonetheless, our technique appears to dominate the existing conventional approaches. This paper covers only a small area of this growing field of research. Hopefully, our investigations to contribute to these efforts by showing that return level dating technique derived from stress-losses model may have a place in the toolbox of economists looking for more accurate techniques in predicting currency crises.
\end{abstract}

Keywords: Periods of currency crisis, EMPI return level, Exchange market pressure, GEV distribution, Kenya's EMPI, RLD technique, conventional method

\section{Introduction}

Dating currency crisis periods stills one of the major preoccupations of economists, financial, banking managers, and even academics and researchers. The survey of currency crisis literature showed that dates of currency crisis used across studies are substantially different from others. In addition there does not exist a theory or a policy agreement between governments and bankers on how to define currency crisis periods. This is due to the non unanimity in determining global currency crisis periods among researchers, the lack of agreement in research methodology on building currency crisis periods and also the lack of one specific accurate approach to analyze currency crisis model. For instance (Pozo \& Amuedo-Dorantes 2003) declared that: "As in the case of all other approaches used to identify currency crisis periods, our approach may not provide an unambiguous standard that can be used to verify that what we identify as a currency crisis is indeed a currency crisis. There is no formal definition of currency crisis derived from theory, and multilateral organizations do not systematically categorize countries or crisis periods". Hence there is no way to grade the accuracy of theses multiple approaches . Jacobs 2007 stated that: "Unfortunately, there is no way to judge the accuracy of currency crisis dating methods, since there is no consensus about a formal definition of currency crisis derived from theory. Moreover, international organizations do not systematically categorize crisis countries or crisis periods". Until today, there does not exist a single theory or specific international policy regulation that can explain this phenomenon and also currency crisis periods dating stills always regional but never been global. 
To determine the severity and the periods of currency crisis, recent literature, like (Eichengreen et al. 1994), (Eichengreen et al. 1996), (Kaminsky, 1999) and (Kaminsky \& Reinhart 1999) first employed a combination of sample mean and standard deviation to identify crisis and non crisis periods, but this approach is not standard since it is based only on the normality assumption. This group defined Currency crisis periods as the period when an index exceeds some upper thresholds of the entire sample 's average value. They talk about currency crisis period over an individual country when its EMP variable takes on an extreme value with respect to all the countries in the sample. In general we have:

$$
\text { Crisis }= \begin{cases}1, & E M P I_{i, t} \geq \beta \sigma E M P I+\mu E M P I \\ 0, & \text { otherwise }\end{cases}
$$

Where $E M P I_{i t}$ is the exchange market pressure indexes for individual country $i$ at period $t$ and $\sigma E M P I$ equals the sample standards deviation of $E M P I_{i t}$ and $\mu E M P I$ the sample mean of $E M P I_{i t}$ and $\beta$ an arbitrary threshold with $1.5 \leq \beta \leq 3$.

Kaminsky, 1999 and (Kaminsky \& Reinhart 1999) studies followed (Eichengreen et al. 1994) and (Eichengreen et al.1996) on identifying currency crisis periods. However, in the selection of the crisis thresholds (Kaminsky 1999) and (Kaminsky \& Reinhart 1999) choose a cut-off points of three (3.0) standard deviation above its mean. Unlike (Eichengreen et al. 1994) and (Eichengreen et al. 1996) who used three, six and twelve months windows; (Kaminsky, 1999) and (Kaminsky \& Reinhart 1999) and others like (Ho, 2008) set a signaling window of currency crisis at two years (24 months) preceding the crisis. Researchers have been following this approach for more than a decade. Though many of them have been aware of not given any justification for their choice. But this method is not standard since it is based only on the normality assumption. It has also been criticized for it arbitrariness in the choice of the crisis threshold.

Some studies have attempted to apply Extreme Value Theory (EVT) in the identification of currency crises, for examples (Pozo \& Amuedo-Dorantes 2003), (Haile \& Pozo 2006), (Ho, 2008) and (Heinz \& Rusinova 2015). In this method they simply used the threshold to identify currency crises periods. However, this approach seems to be confused the thresholds in extreme modeling with the cutoffs of currency crises since the threshold is not necessary the cut off that triggers currency crises, since currency crisis can be regarded as an extreme outcome in the foreign exchange market, but the converse is not always true. (See for instance (Qin \& Liu 2014), (Pozo \& Amuedo-Dorantes 2003), (Haile \& Pozo 2006), (Ho, 2008) and (Heinz \& Rusinova 2015). From their studies, they criticized more the procedure elaborated by (Eichengreen et al. 1996); after a careful examination of table 1 in (Pozo \& Amuedo-Dorantes 2003) page 595, section 3. They finally argue that the use of EVT to identify currency crisis for EMP is consistent since the tail of the distribution of EMP constitute its outliers which are the results of successful pressure against the currency crisis periods.

Another and recent approach proposed an extreme, return levels approach derived from EVT to identify currency crisis for instance (Qin \& Liu 2014). However this approach relaxes the embedded normality and also considered non dependency structure assumptions among the data whereas, most financial time series for example the EMP indexes do not in general satisfy these assumptions because it is observed some dependence over time.

Based on the previous studies listed above, we remark that all of them consider only the independent identically distribution (IID) assumption among the data. Others relaxed the embedded normality assumption i.e. they have considered thin tail of the EMPI distribution. These drawbacks of existing approaches gives an impetus to a new method: ' Estimation of return levels and currency crisis dating periods' which is the main goal of this research.

From recent literature there are no global studies that have been undertaken the identification of currency crisis periods employing the estimation of return levels using generalized extreme value distribution under the assumptions of the dependence structures of the data. Therefore, we further implement a new and suitable technique that can enhance and improve the previous approaches by assuming non normality and dependence of the EMPI model.

Our paper approach undertakes the following Estimation of return levels and currency crisis dating periods. Beside, this study will attempt to employ return level approach using the generalized extreme value models to fit the EMP series and estimate return level to identify currency crisis. The first task is to implement a EMPI return level identification procedure and employ the GEV distribution to estimate the return levels of the EMPI to identify currency crisis periods.

The return levels are estimated assuming GEV distribution using either parametric or semi parametric method to estimate GEV parameters. From previous literature several studies have been elaborated in this area such as (Ribereau et al. 2008), (Persson et al. 2010), (Rust et al. 2011), (Aarnes et al. 2012), (Fawcett \& Walshaw, 2012) and (Shajitha \& Perera, 2014). Recent literature showed that return levels aroused in many engineering areas such as ocean engineering (with the wave height), hydraulics engineering (floods), structural engineering (earthquakes) and in meteorology (temperatures, rainfall ), fatigue strength (workloads) etc... rather than in economy areas. One of the applications in economic areas is currency crises; however, there is a lack of literature about the use of the return levels to identify currency crisis periods. According to recent literature and the author knowledge until now there exists only one study of (Qin \& Liu 2014). 
Notice that the GEV parameters will be estimated employing different parametric and semi parametric methods. To estimate the parameters of a GEV distribution several methods have been developed, studied and compared during the last twenty years for example (Greenwood et al. 1979), (Smith, 1985), (Hosking, 1990), (Coles \& Dixon 1999), (Coles et al. 2001), (Zhang, 2007) and (Ribereau et al. 2008). However, this paper will use a parametric method in particular the maximum likelihood estimator (MLE).

Return levels will also be estimated using one of the following assumptions: First assume that the time series is strictly stationary and satisfies the maximum domain of attraction (MDA) condition, then an extremal index needs to be estimated, that account for clustering of extreme value due to dependence. In this assumption, to estimate the extremal index (Northrop, 2005) proposed an alternative method used to estimate an extremal index. The method called semi parametric estimation of the extremal index using block maxima. He stated that the method is simple and non-iterative, more efficient than its parametric counterpart proposed by (Coller et al. 1991) and the three popular estimators methods known as the block, runs and interval methods discussed in (Ferreira 2015). Therefore, in this paper to determine the extreme index parameters the authors follow the same approach proposed by (Northrop, 2005) in his study. Second, assume that the model is stationary but the MDA condition is not satisfied then in this case no need of extremal index, however another approach is to model the dependence structure fitting some GARCH- type models to the EMPI data (see (Embrechts et al. 1999), (Gencay \& Selcuk, 2004) and (Marimoutou et al. 2009)).

Finally, a sensitivity analysis is given on the estimated return values to analyze and identify the periods of currency crisis. A comparison study between our identification approach and the existing conventional approach in the most literature is also conducted.

We further illustrate the method by an empirical study on identifying currency crisis of Kenya as case study. To quantitatively study currency crisis, the Exchange market pressure index (EMPI) model is described as follow :

Let $E M P_{i, t}$ denotes the EMP index of base country $i$ at time $t$. Let $E_{i, t}, R_{i, t}, I_{i, t}$ be respectively the exchange rate, foreign reserves and interest rate of country $i$ at time $t . R_{c, t}, I_{c, t}$ denote respectively the foreign reserves and interest rate of the reference country $c$ at time $t$. let $\sigma_{E}, \sigma_{R}, \sigma_{I}$ be respectively the standard deviation of $E_{i, t}, R_{i, t}, I_{i, t}$. Assume $\alpha, \beta, \gamma$ be the weights attached to each components $E_{i, t}, R_{i, t}, I_{i, t}$. let $\mu_{i, \Delta_{E}}$ and $\mu_{i, \Delta_{R}}$ denote historical means of percent nominal depreciation and international percent change in the holding of reserves. and $\sigma_{i, \Delta_{E}}$ and $\sigma_{i, \Delta_{R}}$ stand for historical standard deviations of these series for emerging market $i$.

Then, quantitatively the currency crisis is described by the EMPI as follow :

$$
E M P_{i, t}=\alpha \times \frac{\Delta E_{i, t}}{E_{i, t}}-\beta \times \frac{\Delta R_{i, t}}{R_{i, t}}+\gamma \times \Delta I_{i . t}
$$

In the following we enumerate some typical EMPIs derived from past papers. Their compositions differ slightly from the general one in Eq (2).

1. The EMPI of (Sachs et al. 1996) is expressed as:

$$
E M P_{i, t}=\alpha \times \frac{\Delta E_{i, t}}{E_{i, t}}-\beta \times \frac{\Delta R_{i, t}}{R_{i, t}}+\gamma \times \Delta I_{i . t}
$$

Where:

$$
\alpha=\frac{\frac{1}{\sigma_{E}}}{\frac{1}{\sigma_{E}}+\frac{1}{\sigma_{R}}+\frac{1}{\sigma_{I}}}, \quad \beta=\frac{\frac{1}{\sigma_{R}}}{\frac{1}{\sigma_{E}}+\frac{1}{\sigma_{R}}+\frac{1}{\sigma_{I}}}, \quad \gamma=\frac{\frac{1}{\sigma_{I}}}{\frac{1}{\sigma_{E}}+\frac{1}{\sigma_{R}}+\frac{1}{\sigma_{I}}}
$$

2. The EMPI of (Aizenman et al., 2012) is expressed as:

$$
E M P_{i, t}^{s}=\alpha \times\left(\frac{\Delta E_{i, t}}{E_{i, t-1}}-\mu_{i, \Delta_{E}}\right)-\beta \times\left(\frac{\Delta R_{i, t}}{R_{i, t-1}}-\mu_{i, \Delta_{R}}\right)
$$

Where:

$$
\alpha=\frac{1}{\sigma_{i, \Delta_{E}}} \quad \beta=\frac{1}{\sigma_{i, \Delta_{R}}}
$$

3. The alternative $E M P_{i, t}$ of (Mouridi et al, 2018) for a country $i$ at a time $t$ can be written as follows:

$$
E M P_{i, t}=\alpha \times \%\left(\frac{\Delta E_{i, t}}{E_{i, t}}-\mu . \Delta E\right)+\beta \times \Delta\left(I_{i, t}\right)-\gamma \times\left(\frac{\% \Delta R_{i, t}}{R_{i, t}}\right)
$$


Where:

$$
\alpha=\frac{\frac{1}{\sigma_{E} \Delta E}}{\frac{1}{\sigma_{E} \Delta E}+\frac{1}{\sigma_{R}}+\frac{1}{\sigma_{I}}}, \quad \beta=\frac{\frac{1}{\sigma_{I}}}{\frac{1}{\sigma_{E}}+\frac{1}{\sigma_{R}}+\frac{1}{\sigma_{I}}}, \quad \gamma=\frac{\frac{1}{\sigma_{R}}}{\frac{1}{\sigma_{E}}+\frac{1}{\sigma_{R}}+\frac{1}{\sigma_{I}}}
$$

Notice that for practical implement in section three, the authors focus only on one single currency crisis model , the alternative EMP index model defined in Eq (5), for the intent of arbitrating the performance among various techniques.

The rest of the paper is as follow. Section 2 proposes the methodology used to implement the new approach. Section 3 investigates an empirical study on Kenya. A comparison study between the new approach and the existing conventional methods is also presented. Section 4 summarizes the findings and presents some recommendations for future work.

\section{Method}

\subsection{GEV Distribution and the Maxima Method}

The study will discuss only one method, the block maxima approach (BM) to estimate the T-year return levels of extreme exchange market pressure index (EMPI). The study will assume the stress losses model i.e. generalized extreme value (GEV) distribution and it will be fitted to the annual block maxima of exchange market pressure (EMPI) data.

The maxima method consists to divide a giving sample of $\mathrm{N}$ elements into $\mathrm{m}$ sub-samples of $\mathrm{n}$ observations each other (m blocks) and picks the maximum $M_{m}=\max \left\{X_{1}, X_{2}, X_{3}, \ldots, X_{n}\right\}$ of each sub-samples, where $\left\{X_{1}, X_{2}, X_{3}, \ldots, X_{n}\right\}$ is a sequence of independent random variable with the same distribution function say $G$ (Embrechts et al. 1999). The set of extreme value $M$ is then identified with the sequence $\left(M_{m}\right)_{n}$ of block maxima. These resulting peak values of these $n$ block equal length can be used for fitting a suitable distribution to these data and the distribution of maxima of this sequence is studied.

Let $X_{n}$ denotes an independence sequence of random variables with common distribution function $G$ and let $M_{m}=$ $\max \left\{X_{1}, X_{2}, X_{3}, \ldots, X_{n}\right\}$ be the maximum of the sequence $X_{n}$ then

$$
\forall x \in \mathbb{R}, \quad \operatorname{Pr}\left(M_{n} \leq x\right)=G^{n}(x)
$$

The limit low of the block maxima, which we denote by $M_{n}$ with $n$ the size of the sub-sample (block) are giving by the following definition.

Definition 2.1.1: Let $X_{n}$ be a sequence of independent and identically distributed random variables. If there exist constant $a_{n}>0$ and $b_{n} \in \mathbb{N}$ and some non-degenerate distribution function $G$ such that $\operatorname{Pr}\left\{\frac{M_{n}-b_{n}}{a_{n}}\right\}$ converges in distribution to $G$ then $G$ belongs to one of the three standard extreme value distributions (Embrechts et al. 1999) and (Coles et al. 2001).

$$
\begin{aligned}
& \text { Gumbel: } \quad G(x)=\exp \left(-\exp \left(\left(\frac{(x-b)}{a}\right)\right)\right), \quad x \in \mathbb{R} \\
& \text { Frechet: } \quad G_{\alpha}(x)=\left\{\begin{array}{ll}
0, & \text { for } x \leq 0 \\
\exp \left(-\left(\frac{(x-b)}{a}\right)^{\alpha}\right) & \text { for } x>0
\end{array} \alpha>0\right. \text {. } \\
& \text { Weibull: } \quad G_{\alpha}(x)=\left\{\begin{array}{ll}
1, & \text { for } x>0 \\
\exp \left(-\left(-\frac{(x-b)}{a}\right)^{\alpha}\right) & \text { for } x \leq 0
\end{array} \quad \alpha>0\right.
\end{aligned}
$$

Equations (7), (8) and (9) are named the Extreme Value distributions also known as type I, II, and III respectively. We notice that the Frechet distribution has a polynomial decaying tail and therefore fits well heavy tailed distributions. The exponentially decaying tails of the Gumbel distribution characterizes thin tailed distributions. Finally the Weibull distribution is the asymptotic of finite endpoint distribution.

It was usual in the past to adopt one of the three families Equations (7), (8) or (9) and then estimate the parameters of the model. But this way has a weakness. A better analysis can be done combining these three models (7), (8) and (9) into one model. By taking the parameter $\xi=\frac{1}{\alpha}$ due to (Jenkinson, 1955) and (Von Mises, 1936); Weibull, Gumbel and Frechet distributions can be represented in a unified model with a single parameter. This parametrization form, G, is known as the Generalization Extreme Value (GEV) model ( (Embrechts et al. 1999), (Gencay \& Selcuk 2004), (Marimoutou et al.2009) and (Coles et al. 2001)) .

Definition 2.1.2 If there exist constant $a_{n}>0$ and $b_{n} \in \mathbb{N}$ and some non-degenerated distribution function $G$ such that $\operatorname{Pr}\left\{\frac{M_{n}-b_{n}}{a_{n}}\right\}$ converges in distribution to $G$ then $G$ is a distribution of the GEV family.

$$
G_{\xi, \mu, \sigma}(x)=\exp \left[-\left(1+\xi\left(\frac{x-\mu}{\sigma}\right)\right)^{\frac{-1}{\xi}}\right]
$$


The variable $x$ in $\mathrm{Eq}(10)$ is defined such that $1+\xi \frac{(x-\mu)}{\sigma}>0$ and with parameters location $\mu \in \mathbb{R}$ and scale $\sigma>0$. The most important parameter is the shape $\xi$ which indicates the thickness of the tail of the distribution. It provides, exactly the tail behavior of the general extreme value distribution in $\mathrm{Eq}(10)$.

\subsection{Parameters Estimation of the GEV}

The parametric procedure has been employed a range of different methods for instance The quasi-maximum likelihood (QML), the moment estimator (ML), the Probability weighted estimator (PWE), the maximum likelihood (ML) and the generalized probability weighted estimator (GPWE). Indeed, in this paper, parameters of the generalizes extreme value distribution are going to be estimated applying the maximum likelihood estimator (MLE).

\subsubsection{Estimator}

The Maximum Likelihood Estimator (MLE) is a method of estimating the parameters of a model or distribution ( Diebolt, 2008 ) and (Hosking, 1990). Let $X=\left(X_{1}, X_{2}, \ldots, X_{n}\right)$ be a sample of data with probability density function $f\left(X_{i} ; \theta\right)$ where $\theta$ is a $(K \times 1)$ vector of unknown parameters. The likelihood function is defined as the joint density treated as a function of the parameters $\theta$

$$
L(X \mid \theta)=L\left(X_{1}, X_{2}, \ldots, X_{n} \mid \theta\right)=f\left(X_{1}, \ldots, X_{n} ; \theta\right)=\prod_{i=1}^{n} f\left(X_{i} ; \theta\right)
$$

The maximum likelihood estimator, denoted $\widehat{\theta}_{M L E}$ is the value of $\theta$ that maximizes $L(X \mid \theta)$ That is,

$$
\widehat{\theta}_{M L E}=\operatorname{argmax}_{\theta} L(X \mid \theta)
$$

It is quite difficult to directly maximize or minimize $L(X \mid \theta)$. It is often much easier to maximize or minimize the $\log$ likelihood function $\ln (L(X \mid \theta))$; since the function $\ln ($.$) is a monotonic function. Then \mathrm{Eq}$ (11) becomes

$$
\ln (L(X \mid \theta))=\ln \left(\prod_{i=1}^{n} f\left(X_{i} ; \theta\right)\right)=\sum_{i=1}^{n} \ln f\left(X_{i} ; \theta\right)
$$

Recall that in our case study, the probability density function is given by the GEV distribution in Eq (10) say $f\left(X_{i} ; \theta\right)=G E V\left(X_{i} ; \theta\right)$ with $\theta=(\xi, \sigma, \mu)$ where, the corresponding p.d.f. is given by the formula

$$
G_{\xi, \mu, \sigma}(x)= \begin{cases}\frac{1}{\sigma}\left(1+\xi \frac{x-\mu}{\sigma}\right)^{\frac{-1}{\xi}} \exp \left[-\left(1+\xi\left(\frac{x-\mu}{\sigma}\right)\right)^{\frac{-1}{\xi}}\right], & \text { for } 1+\xi \frac{x-\mu}{\sigma}>0 \\ 0, & \text { elswhere }\end{cases}
$$

Replacing Eq (14) into Eq (13), consequently, the likelihood function based on the GEV distribution is given by

$$
L(\theta \mid X)=\prod_{i=1}^{n} g_{\xi, \mu, \sigma}\left(X_{i}\right)=\prod_{i=1}^{n} \frac{1}{\sigma}\left(1+\xi \frac{x-\mu}{\sigma}\right)^{\frac{-1}{\xi}} \exp \left[-\left(1+\xi\left(\frac{x-\mu}{\sigma}\right)\right)^{\frac{-1}{\xi}}\right]
$$

The corresponding log-likelihood $\ln (L(\theta \mid X))$ denoted by $l(\theta \mid X)$ would be

$$
l(\theta \mid X)=-n \ln \sigma-(1+1 / \xi) \sum_{i=1}^{n} \ln \left(1+\xi \frac{x-\mu}{\sigma}\right)-\sum_{i=1}^{n}\left(1+\xi \frac{x-\mu}{\sigma}\right)^{-\frac{1}{\xi}}
$$

With $1+\xi \frac{x-\mu}{\sigma}>0$ and $\xi \neq 0$. In the case $\xi=0$ the log-likelihood function is derived by taking the limit in 0 and given by

$$
l(\theta \mid X)=-n \ln \sigma-\sum_{i=1}^{n}\left(\frac{x-\mu}{\sigma}\right)-\sum_{i=1}^{n} \exp \left(-\frac{x-\mu}{\sigma}\right)
$$

Maximizing the log-function Eq (16) and/ or (17) we obtain the estimated parameters $\widehat{\theta}=(\widehat{\xi}, \widehat{\mu}, \widehat{\sigma})$. In the case $\xi \geq-0.5$, the usual properties of consistency, asymptotic efficiency and asymptotic normality hold. To achieve this objective we should informatively differentiate Eq (16) with respect to the parameters $\theta=(\xi, \mu, \sigma)$ to yields a likelihood system of equations. However, there does not exist an explicit formula for the maximization or say it is more complicated. Therefore, we obtain the estimated parameters by numerically optimizing Eq (16) using one of the numerical methods for example Newton-Raphson algorithm (for more detail see (Hosking 1990)).

A modern account of the theory, including statistical estimation, can be found in (Galambos,1958), (de Haan , 1970), (de Haan \& Ferreira , 2006), (Embrechts et al. 1997), (Resnick, 1987), (Beirlant et al. 2014), etc. The so-important second order condition is explained in (de Haan \& Ferreira, 2006) and revisited in a quantile form in (Lo \& Fall, 2011). 


\subsubsection{Maximum Domain of Attraction (MDA)}

An important concept for the application of extreme value theory is the maximum domain of attraction (MDA).

Let $X_{1}, X_{2}, \ldots X_{n}$ be a sequence of $n$ random variable with density $G(X)$ then:

$$
P\left(\max \left(X_{1}, X_{2}, \ldots X_{n}\right) \leq x\right)=P\left(X_{1} \leq x\right) \times \ldots \times P\left(X_{n} \leq x\right)=G^{n}(X) .
$$

Then

$$
\lim _{n \rightarrow \infty} G^{n}(X)=\left\{\begin{array}{lll}
1, & \text { if } & G(X)=1 \\
0, & \text { if } & G(X)<1
\end{array}\right.
$$

Hence to obtain a non generate distribution we can normalize the maximum. (de Haan \& Fereira 2006)

Suppose there exists a sequence $a_{n}>0$ and $b_{n}$ such that:

$$
P\left(\max \left(X_{1}, X_{2}, \ldots X_{n}\right) \leq a_{n} x+b_{n}\right)=G^{n}\left(a_{n} x+b_{n}\right)
$$

Then

$$
\lim _{n \rightarrow \infty} G^{n}\left(a_{n} x+b_{n}\right)=G(X)
$$

Where $G(X)$ is an non degenerate distribution. Hence if the limits distribution exists, or equivalently if Eq (19) holds for some sequence $a_{n}>0$ and $b_{n} \in \mathbb{R}$ then this limits $G(X)$ is the General extreme value distribution given in Eq (10)(see theorem of Fisher, Tippet and Gendenko theorem 1.1.3 in (de Haan \&Fereira 2006)).

It can be shown from (theorem 1.1.6, lemma 1.1 .9 and corollary 1.2.10 in (de Haan \& Fereirra 2006)) that if $\xi \neq 0$ the following statement are equivalent to $\mathrm{Eq}(19)$ and to each other:

$$
\lim _{t \longmapsto \infty} \frac{U(x)-U(t)}{a(t)}=\frac{x^{\xi}-1}{\xi}, \quad \lim _{t \longmapsto \infty} \frac{U(x)}{U(t)}=x^{\xi}
$$

Where

$$
U(x)=\left(\frac{1}{1-G(X)}\right)^{-1}=G^{-1}(1-1 / x)
$$

Is called the tail quantile function and $a(t)$ is some positive function. Hence the four statements in Eq $(18,19$ and 20$)$ are equivalents. The expressions in Eq (19) are called domain of attraction conditions. Recall that in practice a distribution $\mathrm{G}$ is said to belong to the maximum domain of attraction if the tail index $(\alpha)$ is less than two $(\leq 2)$.

If the distribution $G(x)$ in Eq (10) belongs to $M D A\left(H_{\xi}\right)$, then, for $\xi>0 G(x)$ are called heavy tailed, for instance Pareto, Cauchy, Student-t and Log Gama. For $\xi<0$ the distributions are called short tailed or bounded. These type of distributions have finite right hand end points such as uniform and beta distribution. If $\xi=0$ these distribution are characterized by medium tails or thin tail for example Normal, Gamma and Log Normal ( (Embrechts et al. 1999), (Gencay \& Selcuk 2004), (Marimoutou et al.2009) and (Coles et al. 2001)).

\subsubsection{Dependence Structures}

An important issue raised by the practical implementation of the models studied so far is that for the theory to work, the data must be independent, whereas, most financial time series for example the EMP index in Eq (2) does in general not satisfy this assumption because it is observed some dependence over time. Therefore, the researcher should consider the dependence structure of the data to yield a correct estimate. To assume data dependence one of the two main approaches will be used:

- In the case of dependence structure, when the $D\left(U_{n}\right)$ condition is satisfied we used the extremal index indicator for dependence. The extreme index is a useful indicator of how much clustering of exceedances of a threshold occurs in the limit of the distribution. Essentially, we only have to distinguish between two cases: when the extreme index, $\theta=1$, where there is no tendency to cluster at high levels and large sample maxima from the time series exactly like maxima from similarly-sized IID samples and when the extremal index, $\theta<1$; where there is tendency for extreme value to cluster.

A coherent and accurate method known as Semi parametric method for estimated extremal index using block maxima will be carried out to estimate the extremal index $\theta$. This method is defined as follow (Northrop, 2005):

Let $R=\left(R_{1}, R_{2}, \ldots\right)$ be the rank of the block maxima. $Y=\left(Y_{1}, Y_{2}, \ldots\right)$ be a sequence within $\left(X_{1}, X_{2}, \ldots\right)$. assume a $G\left(\mu_{\theta}, \sigma_{\theta}, \xi\right)$ model for the block maxima then the estimated index parameters $\left(\theta, \mu_{\theta}, \sigma_{\theta}, \xi\right)$ are given by the joint likelihood factor.

$$
L\left(\theta, \mu_{\theta}, \sigma_{\theta}, \xi, R, Y\right)=L \Gamma\left(\theta_{b}\right) \times L G\left(\mu_{\theta}, \sigma_{\theta}, \xi\right)
$$


In this condition the parameters of GEV distribution will be estimated as:

$$
\mu_{\theta}=\left\{\begin{array}{ll}
\mu-\frac{\sigma\left(1-\theta^{-\xi}\right)}{\xi} & \xi \neq 0 \\
\mu+\sigma \log \theta & \xi=0
\end{array} \quad \sigma_{\theta}=\left\{\begin{aligned}
\sigma \theta^{\xi}, & \xi \neq 0 \\
\sigma, & \xi=0
\end{aligned} \quad \text { and } \quad \xi_{\theta}=\xi\right.\right.
$$

Where $\left(\theta, \mu_{\theta}, \sigma_{\theta}, \xi_{\theta}\right)$ are the index parameters and $(\mu, \sigma, \xi)$ are the parameters estimated using the ML with IID condition.

- In the case of dependence structure, when the $D\left(U_{n}\right)$ condition is not satisfied, an alternative method is used employing financial model GARCH type model. In this condition the parameters of GEV distribution will be estimated as:

$$
X_{i}=\mu_{t}+Z_{t} \quad \text { with } \quad Z_{t}=\sigma_{t} e_{t} \quad t=1,2,3, \ldots
$$

Where $\quad e_{t} \sim \operatorname{iidN}(0,1), \quad \mu_{t}=E\left(X_{t}\right) \quad$ and $\quad \sigma_{t}=\sqrt{w+\sum_{k=1}^{p} \beta_{k} \sigma_{t-k}^{2}+\sum_{k=1}^{q} \alpha_{k} Z_{t-k}^{2}}$

The shape parameter $(\widehat{\xi})$ here in this case will be estimated employing one of the numerous non-parametric methods such as Hill estimator, Pickand estimator, adapted Hill estimator, moment estimator and the QQ-estimator. However, the common used estimator are the Hill and Pickand estimators.

Pickand estimator is the first suggested estimator for the shape parameter $\xi$. It is more general and applicable to all three type of limiting distribution. Let $m$ be sequence of integer tending to infinity and let $m / n \rightarrow 0$ as $n \rightarrow \infty$. The estimator is

$$
\widehat{\xi}=\frac{1}{\ln 2} \ln \frac{X_{n-m+1}-X_{n-2 m+1}}{X_{n-2 m+1}-X_{n-4 m+1}}
$$

Hill estimator is the most popular tail index estimator but it is restricted to the case $\xi>0$ (Ho 2008 ). The Hill estimator is given as:

$$
\widehat{\xi}=\frac{1}{m} \sum_{n=1}^{m}\left(\ln X_{n+1-t}-\ln X_{n-m}\right)
$$

Since Hill estimator is restricted only with $\xi>0$. Many studies extended the Hill estimator to more general case $\xi \in \mathbb{R}$ such that adapted Hill estimator, moment estimator and the QQ-estimator ((Embrechts et al. 1999), (Gencay \& Selcuk 2004) and (Marimoutou et al.2009)). Some other popular and remarkable estimators are the Moments estimators of (Dekkers et al. 1989), the Generalized Hill estimator of (Diop \& Lo, 2006, 2009), (Lo \& Dème, 2012) and recently the (Ngom \& LO, 2016)

\subsection{Return Levels Identification Approach}

Considering extreme value of a random variable, the return level of an extreme event, defined as the value, $x_{p}$, such that there is a probability of $p$ that $x_{p}$ is exceeded every year, or alternatively, the level that expected to be exceeded on average once every $T$ year, where $T=1 / p$ is referred to as the return period.

Rootzen and Katz (2013) introduced two concepts of how to estimate the T-year return level also called T-year event. These concepts are related to the methods of annual maximum and the peaks over the threshold. In this work we are interested with the first method the annual maximum as stated in section 2.1.

- The frequency based concept: This method is based on the quantile definition of the return level. Namely, let $X$ be the annual maximum of the variable of interest (EMPI) and its distribution (GEV) be denoted by $G(X)$. Over a period of $T$ years we would have the annual maxima $X_{1}, X_{2}, \ldots, X_{T}$ which are assumed independent and identically distributed variables with stationary assumption. Then the $T$-year event is defined as

$$
x_{T}=G^{-1}(1-P) \quad \text { or } \quad x_{t}=(X: P(X \geq x))=P \quad \text { where } \quad P=1 / T
$$

If the stationary assumption of the model does not hold the distribution function $G(X)$ of the annual maximum should be made dependent on time.

- Waiting-based concept: Rootzen and Katz (2013) defined the waiting-based concept as follows: The return period $T$ is the expected waiting time (in years) until an event with level larger than $x_{T}$ occurs. This is made more precise in (Embrechts, 1999) and (Rosbjerg,1985). Embrechts 1999 defined $X_{i}$ as the annual maximum with distribution $\mathrm{F}(\mathrm{x})$. Let $D(l)$ be integer defined time until level $l$ is exceeded for the first time:

$D(l)=\min \left(i: X_{i}>l\right) \quad$ then $\quad P(D(l)=K)=P\left(X_{1}<l, \ldots, X_{k-1}<l, X_{k}>l\right)=\left(F(l)^{k-1}\right)(1-F(l))=[1-(1-F(l))]^{k-1}(1-$ $F(l)), \quad K=1,2,3, \ldots$ Hence $D(l)$ is Geometrically distributed with parameter $(1-F(l))$. The return period, associated to level $l$ is the expected waiting time until level $l$ is exceeded, hence $T_{l}=E(D(l))=1 /(1-F(l))$. If $T_{l}$ is given one can find 
$l=F^{-1}(1-P=1 / T)$. As it can be expected the relation is the same as in the frequency based concept (Rootzen $\&$ Katz 2013).

\subsubsection{GEV Approach to EMPI Return Levels}

Once the Gev parameters are estimated and the GEV distribution in Eq (10) has been fitted let say by the T-year maximum, in our case study the T-year of the maximum $M_{n}$ of the $E M P I_{i, t}$ then the author can established the EMPI return levels model as in the following:

Assume:

a. $E M P I_{i, t}$ denotes the monthly recording at any country $i$.

b. $M_{n}$ be the yearly maxima of the $\left(E M P I_{i, t}\right)$.

c. $G$ be the GEV distribution of the yearly maxima $\left\{M_{n}\right\}$ of $\left(E M P I_{i, t}\right)$.

Since currency crisis model $E M P I_{i, t}$ is a rare event the researcher takes the unit period to be a window of 12 months. Because the $E M P I_{i, t}$ series, similar to other time series, is observed some dependence structure over time , thus the researcher will assume the dependence structure of the EMPI data. As the distribution of the $E M P I_{i, t}$ series still unknown, the author will employ the domain of attraction conditions of the quantile function.

$$
U(E M P I)=\left(\frac{1}{1-G(E M P I)}\right)^{-1}=G^{-1}(1-1 / E M P I)
$$

Then

$$
\operatorname{Pr}\left(M_{n} \geq(E M P I)_{T}\right)=1-G(E M P I)
$$

Where $(E M P I)_{T}$ be the level that is expected to be exceed in average a T-year. $(E M P I)_{P}$ be the probability of $(E M P I)_{T}$ to reach the expected level in T-year i.e.

$$
(E M P I)_{P}=\frac{1}{T}
$$

The return level $(E M P I)_{T}=\frac{1}{P}$ is the $1-P$ quantile of the distribution $G(E M P I)$. Hence employing the definition of $(E M P I)_{T}$ the EMPI return levels model is given as follows

$$
T\left(1-G\left((E M P I)_{T}\right)\right)=1
$$

According to the frequency based concept or the waiting based concept (or the annual maximum approach) we are interested in the $(1-1 / T=1-P)$ quantile of the distribution of the annual maximum to find the $T$-year event. Then the return levels of the exchange market pressure $(E M P I)_{T}$ will be obtained by solving Eq (27) as following.

$$
G\left((E M P I)_{T}\right)=1-1 / T=1-P, \quad \text { with } \quad P=1 / T
$$

Replacing the distribution $G\left((E M P I)_{T}\right)$ by its value in Eq (10) then Eq (28) becomes:

$$
\begin{aligned}
& \left\{\exp \left[-\left(1+\xi\left(\frac{(E M P I)_{T}-\mu}{\sigma}\right)\right)^{\frac{-1}{\xi}}\right]\right\}=1-P \\
& \exp \left[-\left(1+\xi\left(\frac{(E M P I)_{T}-\mu}{\sigma}\right)\right)^{\frac{-1}{\xi}}\right]=(1-P)
\end{aligned}
$$

Taking logarithm in both sides

$$
\begin{aligned}
& \xi\left(\frac{(E M P I)_{T}-\mu}{\sigma}\right)=1-(\log (1-P))^{-\xi} \\
& (E M P I)_{T}-\mu=\frac{\sigma}{\xi}\left(1-(\log (1-P))^{-\xi}\right)
\end{aligned}
$$

Then the $(E M P I)_{T}$ annual maxima return levels is given as

$$
(E M P I)_{T}= \begin{cases}\mu-\frac{\sigma}{\xi}\left(1-(-\log (1-P))^{\xi}\right), & \text { with } \quad \xi \neq 0, \\ \mu-\sigma \log (-\log (1-p)), & \text { with } \quad \xi=0\end{cases}
$$


In our terminology, Eq (29) is the return levels associated with the return period $T=1 / P$. That is $(E M P I)_{T}$ is the level that is expected to be exceeded, in average, once a $T$-year. Equivalently, $(E M P I)_{P}$ is the level that is exceeded by the $T$ year maximum in any particular $T$-year with probability $P$.

The representation in Eq (29) includes the shape parameter $\xi$, the location $\mu \in \mathbb{R}$, the scale $\sigma \geq 0$.

Replacing the parameters, $\xi, \mu, \sigma$ and $\theta$ by their estimated, $\widehat{\xi}, \widehat{\mu}, \widehat{\sigma}$ and $\widehat{\theta}$ into Eq (29) we will obtain the estimated return levels $(E M P I)_{T}$ as follows.

$$
(\widehat{E M P I})_{T}= \begin{cases}\widehat{\mu}-\frac{\widehat{\sigma}}{\widehat{\xi}}\left(1-(-\log (1-P))^{\widehat{\xi}}\right), & \text { with } \quad \widehat{\xi} \neq 0, \\ \widehat{\mu}-\widehat{\sigma} \log (-\log (1-p)), & \text { with } \quad \widehat{\xi}=0\end{cases}
$$

Now we are highlight some of the theory used to determine both the period $T$ and the probability $P$ employed previously. Recall that the probability of an extreme event can be expressed in its return period $T$.

$$
T=\frac{1}{1-G(E M P I)}
$$

The probability that a $T$-year event $(E M P I)_{T}$ happens to occur in a certain year is given by:

$$
\operatorname{Pr}\left(M>(E M P I)_{T}\right)=1-G\left((E M P I)_{T}\right)=1-(1-1 / T)=1 / T
$$

The value of $(E M P I)_{T}$ is called the return level or the return value. The probability that a $T$-year event happens to occur at least once in a $n$-year period is

$$
\operatorname{Pr}\left(M_{n}>(E M P I)_{T}\right)=1-G^{n}\left((E M P I)_{T}\right)=1-(1-1 / T)^{n}
$$

In which $M_{n}$ is the highest value (the outlier) in a $n$-year period. It then follows:

$$
\begin{array}{ccc}
\operatorname{Pr}\left(M_{n}>(E M P I)_{T}\right) & = & (1-1 / T)^{n} \\
-\ln \operatorname{Pr}\left(M_{n}>(E M P I)_{T}\right) & = & -n \ln (1-1 / T) \\
-\ln \left(-\ln \operatorname{Pr}\left(M_{n}>(E M P I)_{T}\right)\right) & = & -\ln (-\ln (1-1 / T))-\ln (n)
\end{array}
$$

Now let

$$
\Delta(E M P I)_{T}=-\ln \left(-\ln (1-1 / T)^{n}\right)-\ln (n)
$$

Then it follows that

$$
\operatorname{Pr}\left(M_{n}>(E M P I)_{T}\right)=G\left(\triangle(E M P I)_{T}\right)
$$

For all practical situations, Eq (35) can be approximated by

$$
\Delta(E M P I)_{T}=\ln (T)-\ln (n)
$$

Care needs to be taken when $\xi=0$ in this case, as with forming the likelihood in the first place, we should work with the limiting form (as $\xi \longrightarrow 0$ ) of the distribution function.

Of course, a point estimate of the return level alone is not enough; any estimate requires a corresponding standard error. As the return level is a function of the GEV parameters, which we have standard errors for, we can use a technique known as the delta method to obtain standard errors for return level estimates.

$$
\operatorname{var}\left[(E M M P I)_{T}\right]=\nabla(E M P I)_{T}^{T} \Lambda \nabla(E M P I)_{T}
$$

Where $\Lambda$ is the variance co-variance matrix of $(\hat{\mu}, \hat{\sigma}, \hat{\xi})^{T}$ and

$$
\nabla(E M P I)_{T}^{T}=\left[\frac{\partial(E M P I)_{T}}{\partial \mu}, \frac{\partial(E M P I)_{T}}{\partial \sigma}, \frac{\partial(E M P I)_{T}}{\partial \xi}\right]
$$

Further, confidence intervals formed in the usual way are often extremely misleading for return level estimates, owing to the asymmetry encountered in the surface of the likelihood for these quantities; rather, the method of profile likelihood is preferred to construct confidence intervals here.

For return level using the GEV model, the profile likelihood method for determining the return level confidence interval, is implemented as follows: 
1. Re-parametrise the GEV model for $(E M P I)_{T}$ becomes one of the model parameters. In this case Eq(30) becomes:

$$
\widehat{\mu}=(\widehat{E M P I})_{T}-\frac{\widehat{\sigma}}{\widehat{\xi}}\left((-\log (1-P))^{\widehat{-\xi}}-1\right)
$$

Then obtain an expression for the log-likelihood $l\left(\hat{\sigma}, \hat{\xi},\left(E M P I_{T}\right)\right)$ by substituting $\mathrm{Eq}(38)$ into $\mathrm{Eq}(16)$.

$$
l\left(\hat{\sigma}, \hat{\xi},\left(E M P I_{T}\right)\right)=-n \ln \sigma-(1+1 / \xi) \sum_{i=1}^{n} \ln \left(1+\xi \frac{x-\mu}{\sigma}\right)-\sum_{i=1}^{n}\left(1+\xi \frac{x-\mu}{\sigma}\right)^{-\frac{1}{\xi}}
$$

Where $n$ is the number of block maxima and $\mu$ is defined as in $\mathrm{Eq}(38)$.

2. For some fixed lower value of $(E M P I)_{T}=(E M P I)_{T, L o w}$, maximize the GEV log-likelihood in Eq (39)

$$
l\left(\hat{\sigma}, \hat{\xi},(E M P I)_{T}=(E M P I)_{T, L o w}\right)
$$

With respect to the two remaining parameters $(\hat{\sigma}, \hat{\xi})$ to obtain $l_{p}\left((E M P I)_{T}\right)$ at $(E M P I)_{T, L o w}$. Where

$$
(E M P I)_{T, L o w}=G^{-1}\left(1-p, \hat{\sigma}, \hat{\xi},(E M P I)_{T}\right)
$$

3. Repeat step (2) for a range of value $(E M P I)_{T}$ for $(E M P I)_{T, L o w} \leq(E M P I)_{T} \leq(E M P I)_{T, U p}$ with

$$
(E M P I)_{T, U p}=-G^{-1}\left(1-p, \hat{\sigma}, \hat{\xi},(E M P I)_{T}\right)
$$

4. Plot $l_{p}\left((E M P I)_{T}\right)$ against $(E M P I)_{T}$ to give the profile log likelihood curve for $(E M P I)_{T}$

\subsection{EMPI Return Levels Dating Procedures}

A discussion and analysis of the resulting estimated return levels will be given to identify the periods of currency crisis. In this work a calculated return periods corresponding to an extreme return levels will be linked to develop a decision tool or framework for identifying the different periods affected by speculative attack (currency crisis).

The approach will adopt the concept from return levels into this currency crisis setting. Therefore, the T-period return level of the EMPI represents the level of EMPI on average to be reached one time every T-year and hence is the new critical value of successful currency crisis period following our new return level identification technique (RLDT)

The theoretical approach to return levels estimation in this study uses the two concepts of the $T$-year event described above and the annual maxima approach from section (2.2.1). Furthermore, we develop a general procedure to define currency crisis periods return levels dating as follow:

Step 1: Collect data on exchange rates, foreign reserves, and interest rates on the base contry, and the reference country as well if the EMPI requires;

Step 2: Construct the EMPI series $\left(E M P I_{i, t}\right)$ with a specified frequency for example yearly, quarterly using an exchange market pressure index model and its transformations.

Step 3: Diagnostic the EMPI model properties built in step 2, i.e. to check either:

a. The data follow a thin, short or fat-tail distributions.

b. The model is stationary or non-stationary.

c. The model presents a ARCh or GARCH effects.

Step 4: Fit the annual maxima EMPI model. In this step a window or a frequency should be specified (e.g: monthly or yearly windows)

Step 5: Fit the generalized extreme value distribution to the annual maxima and get the estimates parameters $\xi, \mu$ and $\sigma$ by the MLE or MME etc...

Step 6: Diagnostic test the estimated shape parameters $\xi$ i.e. check if $\xi<0, \xi=0$ or $\xi>0$ to know which distribution is corresponding.

Step 7: Use diagnostic plot to check goodness of fit (check model adequacy). 
Step 8: Diagnostic serial correlation i.e. estimates the extreme index $\theta \in[0 ; 1]$.

a. If $\theta=1$ then assume independence structure

a. If $\theta<1$ then assume dependence structure

Step 9: If $\theta<1$ then verify the existence of the maximum domain of attraction conditions. If $M_{n} \in M D A\left(G_{\xi}\right)$ then assume IID, if not, assume dependent structure. In this case we estimate the parameters in step 5 using GARCH or ARCH models.

Step 10: Calculate the $T$-year return level $(E M P I)_{T}$ using equation (42), the return period and the corresponding probability as well if it is required.

Step 11: Estimates the standard error and the confidence interval for the $T$-year return level and parameters, then plot the return levels and parameters for diagnostic.

Step 12: Obtain the currency crisis periods with EMPI higher than the $T$-year return level $(E M P I)_{T}$. If more than one currency crisis are detected within a specified window, only one currency crisis is selected, those within the confidence interval of the return level $(E M P I)_{T}$

The nice property of the return level identification technique is that it does not require assumptions on the parametric form of the parent distribution, naturally enables our model to be a better alternative to the traditional model which arbitrary assumes an IID structure and normal distribution. Note that, steps (3), (8) and (9) are highly recommended to be investigated; since these characteristics are very common in economic models rather than in other models. All the steps are not compulsory some can be omitted however, the order of the steps are important for a better performance of the technique.

\section{An Empirical Study: Kenya's EMPI}

\subsection{Data Description}

To illustrate how to implement our new approach and to evaluate its performance in practice as well, we explore an empirical study on Kenya as special case of study, which rarely lies in the scope of the majority of studies on currency crisis. We notice that, of course, our study here could be easily extended to other countries. Thus our study here also will demonstrate as evidence on whether Kenya has indeed experienced with currency crisis or no currency crisis.

The main source of all data is the Kenya National Bureau of Statistics (KNBS) and the Central Bank of Kenya (CBK). The choice of this country is motivated by first the possibility or availability of the data. Secondly few study have taken the study of currency crisis employing the method of exchange market pressure in Kenya. Means, Kenya rarely lies in the scope of the majority of studies on currency crisis.

The author collects monthly data for the period covered span eighteen (18) years and half from the fall of January 1999 to April 2017, which includes several depreciation on the exchange rates. We will end up with a balance panel data set of 12 months for eighteen years plus four months for the year 2017, which make a total of 216 observations. The author employs monthly data instead of yearly data to get sufficient observation for the application of general extreme value (GEV) distribution since the tail index is invariant to the frequency of the data or time aggregation.

The data collected include: Exchange rate (E), International reserves $(R)$ and the domestic interest rates (I). The exchange rate used in the index model is measured relative to the central Bank of Kenya (CBK). The author collects both Dollar and Euro versus Shillings Figure 1. Noting that they both are among the top trading partners to Kenya.

The Exchange rate data are collected at the end of each month. We also collect the monthly average for both Dollar and Euro. The Domestic interest rates are measured relative to Kenya central bank rates. International reserves are calculated according to the definition of the Kenya monetary authority (KMA) figure 2 .

The three components Exchange rate (E), International reserves (R) and the Domestic interest rates (I) mentioned above are all measured in terms of the Kenyan Shillings. Data from published papers and research workers especially the KNBS and CBK published papers are also used in the necessary to provide baseline parameter values that can not be obtained. We, then can get two monthly Kenya's EMPI series from the MMH model ( Mouridi et al. 2018) in Eq (3) with different indexes and currencies (see figure 3).

Before proceeding to the new technique mentioned above, we could show the setup of using the traditional currency crisis identification in Eq (1) and of assuming normality for the currency crisis analysis. Table 1 lists some descriptive statistics of the EMPI series for both USD and EURO samples data. The skewness, the kurtosis results as well as the formal Jarque-Berra test on normality give a good evidence that the null hypothesis of normality of the EMPIs is rejected with very high level of confidence (above $90.5 \%$ ) in both cases. 


\section{USD versus $\mathrm{KSH}$ Exchange rates}

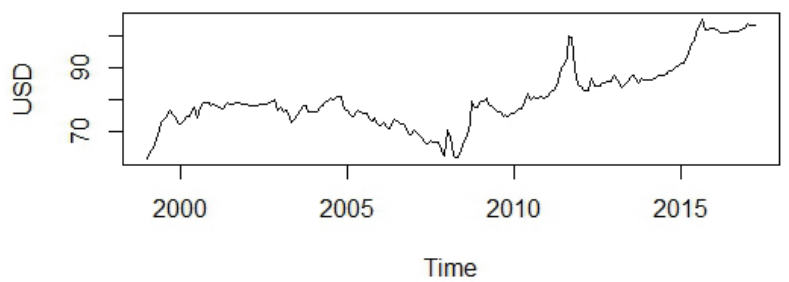

EURO versus KSH Exchange rates

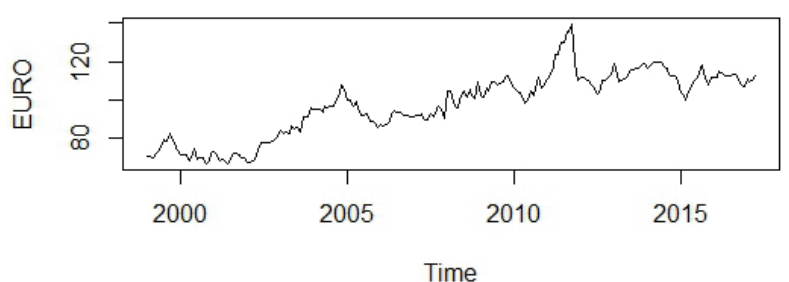

Figure 1. Dollar \& Euro versus KSH exchange rates

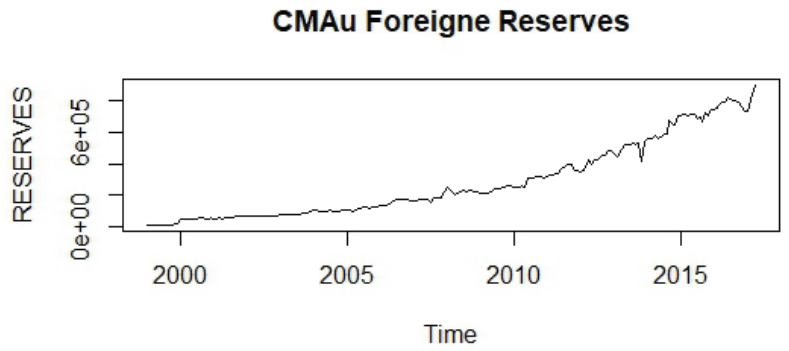

CBK Interest Rates

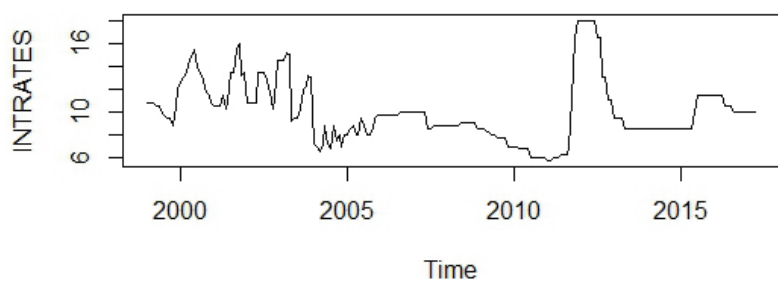

Figure 2. Foreign reserves and Interest rate data

Table 1. Descriptive statistics of EMPIs, 1999-2017

\begin{tabular}{lcccccc}
\hline EMPI & Mean & Median & Standard deviation & skewness & Kurtosis & Jarque-Bera \\
\hline USD & 0.00319 & 0.0028 & 0.41 & -0.571 & 15.51 & 1442.2 \\
EURO & 0.00024 & 0.0016 & 0.40 & -0.572 & 15.52 & 1442.7 \\
\hline
\end{tabular}

This implies that the new approach(RLDT) can be widely used regardless the type of the distribution, means that even in the normality or IID cases the RLDT can be still used as a special when the maximum domain of attraction condition satisfied. 
DOLLAR EMP Index

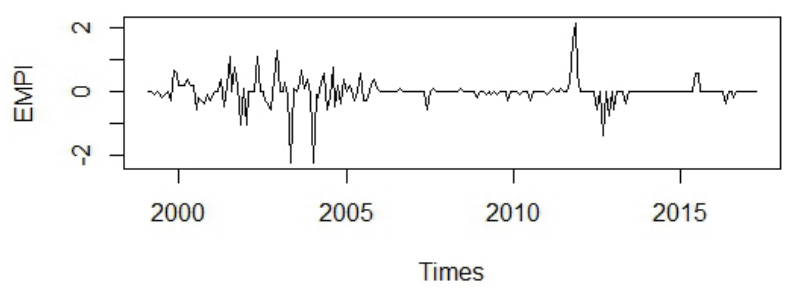

EURO EMP Index

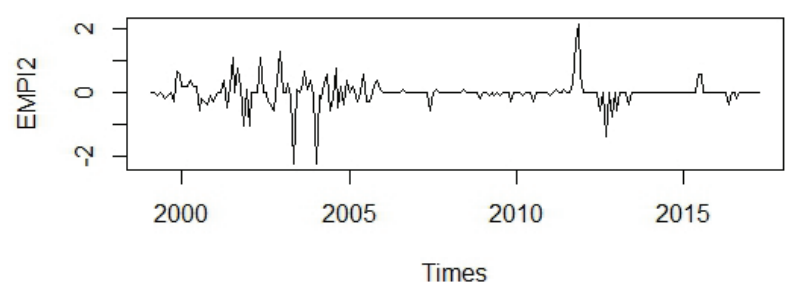

Figure 3. Dollar and Euro Kenya EMPIs

\subsection{Return Level Estimation}

The distribution that the data are from is, of course, not the normal distribution according to the results obtained in Table 1. Although, we still are not quite sure which distribution our data come from. However, the results of the kurtosis in Table 1 show that short-tailed distributions are probably a reasonable good approximation for our model. Furthermore, the EMPIs time series in figure (3) present a finite right end points, implies that their distributions belong to the short tailed list of distribution such as uniform and beta distributions. To fit this condition our study will therefore, rely in general on one of the extreme value theory distributions. i.e. the generalized extreme value (GEV) distribution.

In this work, the authors chose the length of the sequence to be 12 months which is equal to a year. The three parameters $(\hat{\xi}, \hat{\mu}, \hat{\sigma})$ of the GEV distribution are estimated using the MLE.

Table 2. Fitting the EMPIs GEV distribution by the ML estimator

\begin{tabular}{lcccc}
\hline EMPI & $\widehat{\xi}$ & $\widehat{\alpha}$ & $\widehat{\mu}$ & $\widehat{\sigma}$ \\
\hline USD & $-0.2032643(0.01131)$ & -4.919703 & $-0.1587639(0.03624)$ & $0.5060075(0.01974)$ \\
EURO & $-0.2029396(0.01124)$ & -4.927575 & $-0.1617036(0.036227)$ & $0.5052941(0.01965)$ \\
\hline
\end{tabular}

Table 2 provides both EMPIs GEV estimated parameters for the maximum likelihood estimator viz the shape parameter $(\hat{\xi})$, the tail index $(\hat{\alpha})$, the location $(\hat{\mu})$ and the scale $(\hat{\sigma})$. Column 1 and 2 present the estimated shape parameters and the respective tail index determined by the fitted GEV distribution using the MLE. The results in table 2 for both EMPIs show negative value for the shape parameters. In addition their values exceed -0.5 , suggest the presence of a short tail in both EMPIs. The highest value of $(\hat{\xi})$ is observed for the USD EMPI compared to the EURO EMPI.

Based to the estimated tail index (shape parameter) in table 2, following definition (2.1.1) we conclude that our EMPIs follow a short tailed distribution. The maximum likelihood estimates of the generalized extreme value distribution (GEV) for both EMPIs point to short tailed distributions as suggested above by figure 3 .

The value obtained for tail index $(\hat{\alpha})$ by the method described above in section(.2.2.1) are displayed in table 3 . In all cases, the estimated $\hat{\alpha}$ is $(\alpha \leq 2)$, suggesting that the distribution of EMPIs are in the domain of attraction of stable law.

Table 3. Confidence interval for $\hat{\alpha}$ of both EMPIs

\begin{tabular}{lccc}
\hline EMPI & $\hat{\alpha}$ & Sd error & Confidence intervals \\
\hline USD & -4.919703 & 0.01131824 & $-4.921199 \leq \hat{\alpha} \leq-4.918207$ \\
EURO & -4.927575 & 0.01124943 & $-4.932633 \leq \hat{\alpha} \leq-4.922516$ \\
\hline
\end{tabular}

To ascertain the statistical significance of these results, we construct a 95\% confidence interval for our estimated $\hat{\alpha}$. These 
are displayed in table 3 and we found that in both cases, the confidence interval estimates do not contain the value 2 , suggesting that the distributions of EMPI USD and EURO belong to the domain of attraction of the stable law.

To ascertain the statistical significance of the above results, we calculate approximate value for the extreme index of the EMPIs at $99 \%$ quantiles.

Table 4. Parameter values for the EMPIs extreme index

\begin{tabular}{lccccc}
\hline EMPI & quantiles & $\mathrm{N}$ & $\mathrm{K}$ & $\mathrm{k} / \mathrm{n}$ & Theta $=\theta$ \\
\hline USD & $99 \%$ & 6 & 4 & $4 / 6$ & 0.7434227 \\
EURO & $99 \%$ & 6 & 3 & $3 / 6$ & 0.5393323 \\
\hline
\end{tabular}

Table 4 provides parameters values for both EMPIs extremal index. $N$ represents the number of observations for the EMPI exceeding a specific threshold. $K$ represents the number of tail observations, $K / N=\theta$ is the extreme index at 0.99 quantiles. According to the results of Table 4, we found that the value of the extremal index $\theta$ at 0.990 quantiles is less than $1(\theta \leq 1)$ suggests that there is some dependency in the limit of the distribution. Therefore, the researcher would consider the dependence structure of the data to yield a correct estimate.

From table 2 and table 4 we reformulate the estimated GEV parameters using Eq (23) section (2.2.3).

Table 5. Parameter values for the EMPIs GEV distribution with extreme index

\begin{tabular}{lccc}
\hline EMPI & $\widehat{\xi}_{\theta}$ & $\widehat{\mu}_{\theta}$ & $\widehat{\sigma}_{\theta}$ \\
\hline USD & -0.2032643 & -0.01353861 & 0.5373554 \\
& $(-0.356265,-0.194896)$ & $(-0.090837,0.071542)$ & $(0.481403,0.593395)$ \\
EURO & -0.2029396 & 0.1314667 & 0.5727302 \\
& $(-0.289166,-0.126132)$ & $(0.061321,0.237299)$ & $(0.518531,0.640689)$ \\
\hline
\end{tabular}

Table 5 presents the estimated values of the GEV distribution calculated at extreme points. We notice that the $95 \%$ confidence intervals for the shape parameter $\xi$ for both Dollar and Euro do not include the value zero $\left(-0.356265 \leq \hat{\xi}_{\theta} \leq\right.$ $-0.194896)$ and $\left(-0.289166 \leq \hat{\xi}_{\theta} \leq-0.126132\right)$ respectively. That makes sens, because the underlying distribution has much short tail than a normal as it has been suggested above. The type III extreme value distribution is theoretically the correct one as the shape parameter $\xi$ becomes negative.

As discussion in section 2.3 our interest usually lies not in estimates the GEV parameters themselves but also the use of the fitted model to estimate the $(E M P I)_{T}$ return level that is expected to be exceed in average every T-year and the $(E M P I)_{P}$ return period affected by that level.

The next step is to calculate the appropriate level $(E M P I)_{T}$ and to this end, we follow the classical model given in Eq (30) on the basis of return level. We assume further that we require to have an estimate of the exchange market pressure level we might expected to be exceed once in two (2), five (5) and teen (10)years. The expected EMPIs return levels for both Dollar and Euro are estimated and given in table 6 as well as their corresponding periods $T$.

Since the estimated shape parameter at extreme index $\xi \leq 0$, it leads to an bounded distribution in the return level plot and the evidence for this is pretty strong, since the $95 \%$ interval for $\xi$ is exclusively in the negative domain. On the next, we draw the diagnostic plots for the fitted GEV at extreme points and the return plot for the model figures 4 and 5. Since out of the diagnostic plots the probability plot and quantile plot are approximately linear and the straight line fits almost all the data points, it is safe to conclude that the chosen GEV with the assumption of dependency (means at extreme points) fits the data points pretty well and that the model we chose is valid. We also draw the return level plot separately so that the plot is larger and clearer to see. You can easily find the 2-year, 5-year and 10-year return level $(E M P I)_{T}$ in the plot.

Table 6. Return level values of the EMPIs, 1999-2017

\begin{tabular}{lccc}
\hline EMPI & \multicolumn{3}{c}{ Return levels } \\
\hline period T & 2 & 5 & 10 \\
USD & 0.1762517 & 0.6811841 & 0.9568982 \\
EURO & 0.3337631 & 0.8720952 & 1.1661380 \\
\hline
\end{tabular}

Thus, an estimate of the expected highest EMP values that launch (release) or start the begining of a currency crisis are might be about $(0.1762517,0.6811841$ and 0.9568982$)$ and $(0.3337631,0.8720952$ and 1.1661380$)$ to get the once in 2 , 5 and 10 years for the Dollar and Euro respectively. 

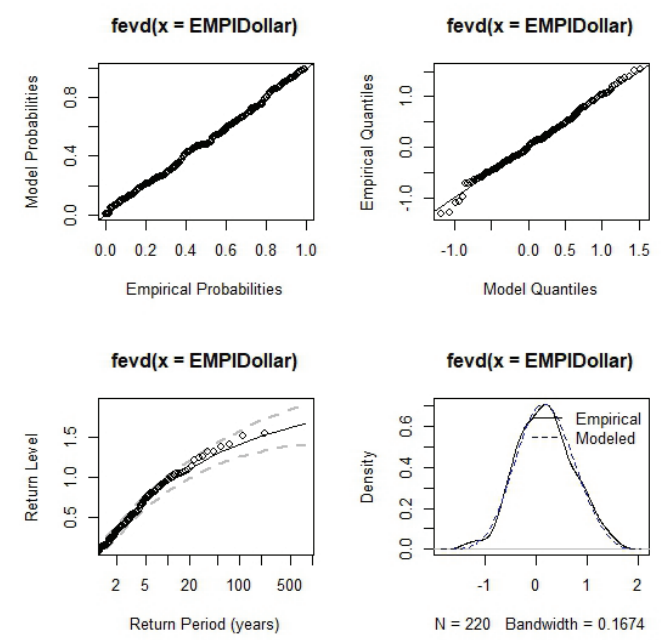

Figure 4. Diagnostic plots indicating the goodness of fit of the GEV to the EMPI Dollar.
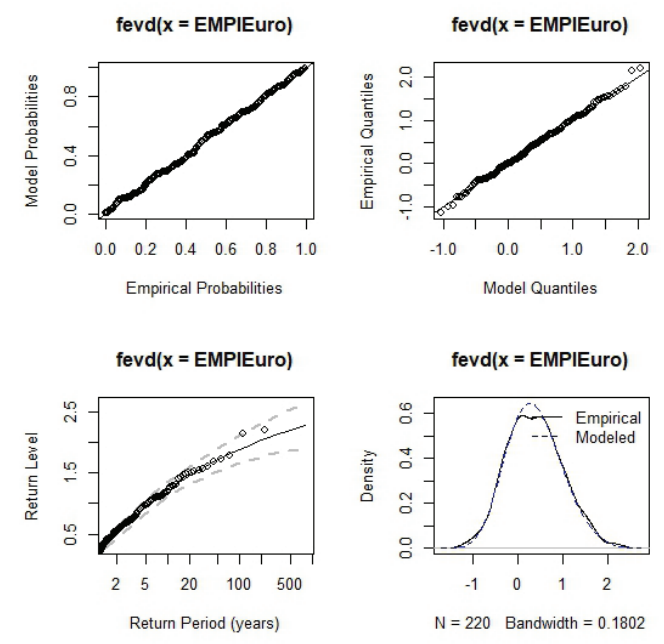

Figure 5. Diagnostic plots indicating the goodness of fit of the GEV to the EMPI Euro.

\subsection{Results and Comparison}

Table 7 provides the results from two different identification techniques; the traditional one and the new technique one known as the return level dating technique (RLDT) which is the scope of our study. The values in parentheses are the return level confidence interval calculated at $95 \%$ for both techniques.

Table 7. Critical values of the Dollar and Euro EMPIs under the traditional and RLDT approaches

\begin{tabular}{lcccc}
\hline EMPI & Traditional & \multicolumn{3}{c}{ RLDT } \\
& Threshold & 2 & Periods T & 10 \\
USD & 1.75 & 0.1762517 & 0.6811841 & 0.9568982 \\
& 0.72069 & $(0.105,0.2621)$ & $(0.5616,0.7414)$ & $(0.8144,0.9855)$ \\
EURO & $0.666511,0.774868)$ & 0.3337631 & 0.8720952 & 1.1661380 \\
& 0.70024 & $(0.2712,0.4458)$ & $(0.7871,1.001)$ & $(1.0898,1.3068)$ \\
\hline
\end{tabular}

(Berg et al, 2005) study stated that "it should be a qualification for a good identification approach to gives out a similar rather than conflicting results towards the same periods regardless of the choices of the indexes and anchor currency". From table 7 a slight difference can be signaled in the two cases USD and Euro between the results under our (RLDT) technique and under conventional approach, such that the traditional critical value lie a way from the confidence interval 
of the (RLDT) technique; when the return level period is considered big. This results may be caused by the assumption of normality in the traditional approach.

Table 8. Currency crisis identified by traditional and RLDT approaches

\begin{tabular}{ccccc}
\hline EMPI & USD & \multicolumn{2}{c}{ EURO } \\
\hline & Traditional & RLDT & Traditional & RLDT \\
2000 & 2002 & 2000 & 2002 \\
2002 & 2003 & 2002 & 2003 \\
2003 & 2012 & 2003 & 2005 \\
2012 & 2016 & 2005 & 2010 \\
2016 & & 2010 & 2012 \\
& & & 2012 & 2016 \\
& & & 2016 & \\
\hline
\end{tabular}

Table 8 shows that the number of crisis under conventional method spreads between five for Dollar and seven for Euro with common currency crisis in 200, 2002, 2003, 2012 and 2016 whereas, results indicate that the common currency crisis episodes dated by our RLDT technique for Kenya from January 1999 to April 2017 are 2002, 2003, 2012 and 2016. We consider a period a common crisis if it is identified by both currency USD and Euro. Note that we define a period by taking a windows of 12 months i.e. one year.

Our technique is pretty more inactive to the choice of currency and presents more consistent results between these two currencies. This is may be due to the capability of EVT for capturing the behavior of all tails of any distribution. It is also due to the assumption of dependency structure among the data.

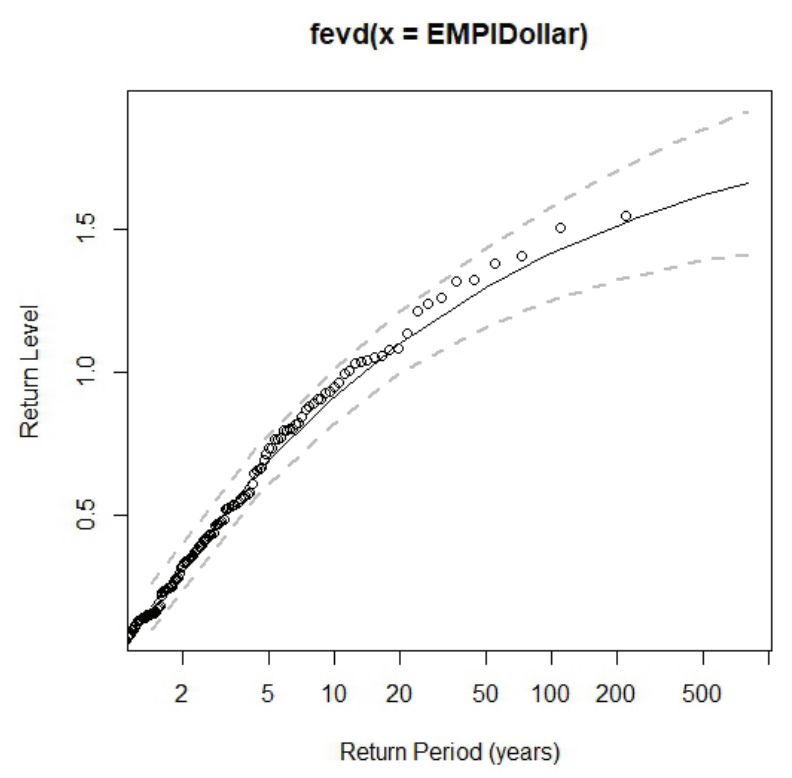

Figure 6. Return levels plot for the EMPI Dollar.

Backward-looking, these dated crisis episodes by our new technique can be viewed as the direct outcomes of several unusual economic and political events. Although, in this period of study Kenya has experienced more unusual geopolitical events which may cause an uncommon direct outcomes in their currency and/ or economy especially in 2004, 2008 and 2015 political crisis. It can also be viewed as the very fast growth of the foreign market especially the Euro market. 


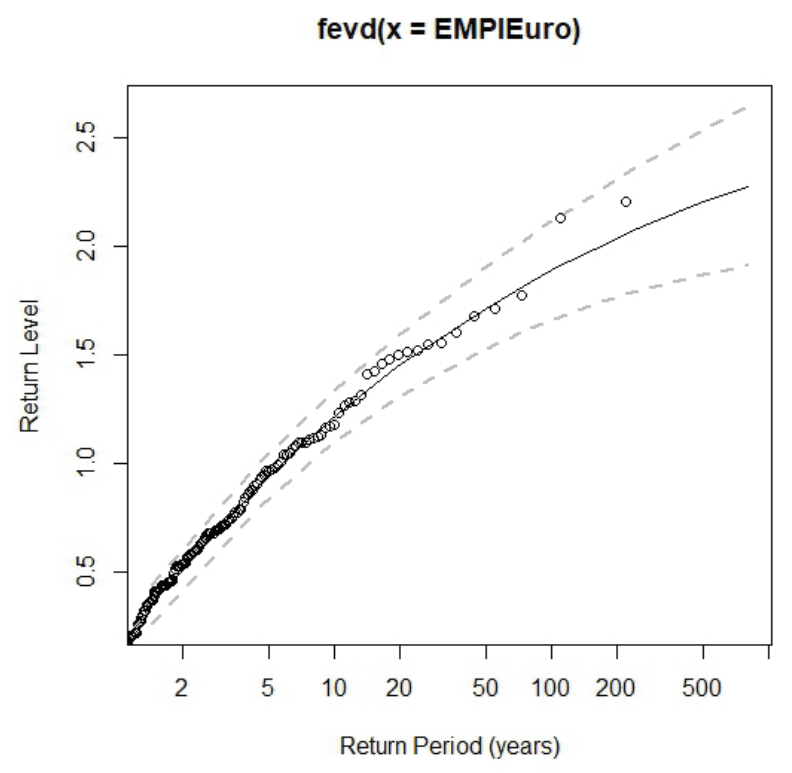

Figure 7. Return levels plot for the EMPI Euro.

\section{Conclusion}

Dating currency crisis periods stills one of the major preoccupations of economists, financial, banking managers and researchers. The survey of currency crisis literature showed that dates of currency crisis used across studies are substantially different from others. The existing conventional approaches for dating currency crisis or non crisis periods are found to have several troubles. Recent studies have been applied extreme value theory others employed even return level identification methods however, these approaches have been more criticized in the most previous literature. These drawbacks and pitfalls of existing approaches give much rise to conduct a new technique which is the main goal of this study. This paper employed return level procedure derived from the stress losses i.e. the generalized extreme value model.

The study also analyzed and compared two currency crisis dating techniques. To judge the quality of a method, we investigated whether the Kenya has (has not) experienced a currency crisis in the periods between January 1999 to April 2017. On the basis of this assessment, we tend to prefer the use of the alternative exchange market pressure index model stated in $\mathrm{Eq}(5)$ section 1 with the assumption of non normality and dependency structure.

By investigating an empirical study on Kenya we reveal that since the estimated shape parameter at extreme index $\xi \leq 0$, it leads to an bounded distribution in the return level plot and the evidence for this is pretty strong, since the $95 \%$ interval for $\xi$ is exclusively in the negative domain. On the next, since out of the diagnostic plots the probability plot and quantile plot are approximately linear and the straight line fits almost all the data points, it is safe to conclude that the chosen GEV with the assumption of dependency fits the data points pretty well and that the model we chose is valid.

We know from the return level part above that the $95 \%$ confidence interval for the 2-year and 5-year return levels of the monthly exchange market pressure index $(E M P I)_{T}$ are $[(0.105,0.2621],[0.2712,0.4458]$ and $[0.516,0.7414],[0.7871$, 1.001] for Dollar and Euro respectively. It just means: we are $95 \%$ confident to say that the maximum monthly exchange market pressure index for Dollar and Euro within 2- years an 5- years will fall both between 0.105 and $0.2621,0.2712$ and 0.4458 and 0.516 and $0.7414,0.7871$ and 1.001 respectively. Similarly, the 10-year return level of the monthly exchange market pressure index $(E M P I)_{T}$ are $(0.8144,0.9855)$ and $[1.0898,1.3068]$ for Dollar and Euro respectively. It just means: we are $95 \%$ confident to say that the maximum monthly exchange market pressure index for Dollar and Euro within 10year will fall both between 0.8144 and 0.9855 ) and 1.0898 and 1.3068 respectively. Although the range is pretty wide, we can still conclude that the maximum exchange market pressure for dollar and Euro will most likely never reach $1.5 \%$ unity and $2 \%$ unity in Kenya even within 10 years. Therefore, we know what we are up to and take some precautionary measures in the event of extremely high exchange market pressure.

We compared the performance of the (RLDT) technique with the conventional method to date currency crisis and no crisis. The number of crisis episodes computed employing these two techniques for the Kenya USD and Euro in our sample are resumed in table 8. According to the result of the return level observed and the range of the return level confidence 
interval, we revealed that the approach demonstrates more consistency and robustness when applied to Kenya. We notice that the technique could be applied to other EMPIs. We hope it will be more accurate and robust and gives adequate results. Thus, we safe to conclude that Kenya exchange markets have experienced with a common currency crises during the periods 2002,2005, 2012 and 2016 for both dollar and Euro exchange markets respectively. Backward-looking, these dated crisis episodes by our new technique can be viewed as the direct outcomes of several unusual economic and political events. Although, we revealed much more in-variance with respect to the EMPIs distributions and significant consistency over the two types of currency under our technique. Whereas no such pretty consistency but conflicting results are derived with the conventional approach comparing to our method.

In sum, we have identified a promising method to date currency crisis employing return level derived from general extreme value model within the extreme value theory, which may help us to better measure speculative pressures and understanding the spreading of currency crisis. The results also appear to confirm the benefits of applying return level technique analysis for more precise selection of currency crisis periods observations in short tailed series. As the case for all other approaches employed to date currency crisis periods our approach may not provide a clear standard that can be used to check that what we date as a currency crisis is in fact a currency crisis. Thus, there is no way to rank the validity of this technique. Nevertheless, our technique appears to monopolize the existing conventional approaches since there is no formal definition of currency crisis derived from theory, and organizations do not systematically classified crisis periods or crisis economies.

This paper covers only a small area of this growing field of research. Hopefully, our investigations to contribute to these efforts by showing that return level dating technique derived from stress-losses model may have a place in the toolbox of economists looking for more accurate techniques in predicting currency crises periods.

\section{Acknowledgements}

This study is supported by the Pan African University (PAUSTI) in collaboration with JKUAT university. The authors are very grateful and extend their appreciations to everyone who contributes for the execution of this work.

\section{References}

Aizenman, J., Lee, J., \& Sushko, V. (2012, September). From the great moderation to the global crisis: exchange market pressure in the 2000s. Open Economies Review, 23(4), 597- 621. https://doi.org/10.1007/s11079-011-9228-y

Berg, A., Borensztein, E., \& Pattillo, C. (2005, July). Assessing Early Warning Systems: How Have They Worked in Practice? IMF Econ Rev, 52(3), 462-502. https://doi.org/10.2307/30035972

Coles, S., Bawa, J., Trenner, L., \& Dorazio, P. (2001). An introduction to statistical modeling of extreme values, volume 208. Springer. https://link.springer.com/book/10.1007/978-1-4471-3675-0

Coles, S. G., \& Dixon, M. J. (1999). Likelihood-based inference for extreme value models. Extremes, 2(1), 5-23. https://doi.org/doi.org/10.1023/A:100990522

Coller, B. S., Scudder, L. E., Beer, J., Gold, H. K., Folts, J. D., Cavagnaro, J., Jordan, R., Wagner, C., Iuliucci, J., Knight, D., et al. (1991). Monoclonal antibodies to platelet glycoprotein iib/iiia as antithrombotic agents. Annals of the New York Academy of Sciences, 614(1), 193-213.

de Haan, L. (1970). On regular variation and its application to the weak convergence of sample extremes. Mathematical Centre Tracts, 32, Amsterdam. (MR0286156)

de Haan, L., \& Ferreira A. (2006). Extreme value theory: An introduction. Springer. (MR2234156)

Dekkers, A. L. M., Einmahl, J. H. J., \& de Haan, L. (1989). A moment estimator for the index of an extreme-value distribution. Ann. Statist. 17(4), 1833-1855.

Diop, A., \& Lo, G. S. (2006). Generalized Hill's Estimator. Far East J. Theo. Stat. 20(2), 2006, 129-149.

Diop, A., \& Lo, G. S. (2009). Ratio of generalized Hill's estimator and its asymptotic normality theory. Math. Method. Statist., 18(2), 117-133. (MR2537361)

Eichengreen, B., Rose, A. K., \& Wyplosz, C. (1994). Speculative attacks on pegged exchange rates: an empirical exploration with special reference to the European monetary system. Technical report, National Bureau of economic research.

Eichengreen, B., Rose, A. K., \& Wyplosz, C. (1996). Contagious currency crises. Technical report, National bureau of economic research.

Eichengreen, B., \& Rose, A. K. (1998). Staying afloat when the wind shifts: External factors and emerging-market banking crises. Technical report, National Bureau of Economic Research. 
Embrechts, P., Kluppelberg, C., \& Mikosch, T. (1999). Modelling extremal events. British Actuarial Journal, 5(2), 465-465. https://link.springer.com/book/10.1007/978-3-642-33483-2

Fawcett, L., \& Walshaw, D. (2012). Estimating return levels from serially dependent extremes. Environmetrics, 23(3), 272-283. https://doi.org/10.1002/env.2133

Ferreira, M. (2015). Estimating the extremal index through the tail dependence concept. Discussiones Mathematicae Probability and Statistics, 35(1-2), 61-74. http://hdl.handle.net/1822/46967

Galambos, J. (1985). The Asymptotic theory of Extreme Order Statistics. Wiley, Nex-York. (MR0489334)

Gencay, R., \& Selcuk, F. (2004). Extreme value theory and value-at-risk: Relative performance in emerging markets. International Journal of Forecasting, 20(2), 287-303. https://doi.org/10.1016/j.ijforecast.2003.09.005

Greenwood, J. A., Landwehr, J. M., Matalas, N. C., \& Wallis, J. R. (1979). Probability weighted moments: definition and relation to parameters of several distributions expressable in inverse form. Water Resources Research, 15(5), 1049-1054.

Haile, F. D., \& Pozo, S. (2006). Exchange rate regimes and currency crises: an evaluation using extreme value theory. Review of International Economics, 14(4), 554-570. https://doi.org/10.1111/j.1467-9396.2006.00643.x

Heinz, F. F., \& Rusinova, D. (2015, July 9). An alternative view of exchange market pressure episodes in emerging Europe: an analysis using extreme value theory (EVT). ECB Working paper No 1818. https://ssrn.com/abstract=2628734.

Ho, T.-k. (2008), Extremal analysis of currency crises in Taiwan. Applied Economics, 40(9), 1175-1186. https://doi.org/10.1080/00036840600771221

Hosking, J. R. (1990). L-moments: analysis and estimation of distributions using linear combinations of order statistics. Journal of the Royal Statistical Society. Series B (Methodological), pages 105-124.

Jacobs, J. P. (2007). Dating currency crises with ad hoc and extreme value based thresholds: East Asia 1970-2002 [dating currency crises]. International Journal of Finance E Economics, 12(4), 371-388. https://doi.org/10.1002/ijfe.316

Kaminsky, G. L. (1999). Currency and banking crises: the early warnings of distress. Number 99-178. International Monetary Fund.

Kaminsky, Graciela, L., \& Carmen M. Reinhart. (1999). The Twin Crises: The Causes of Banking and Balance-ofPayments Problems. American Economic Review, 89(3), 473-500. https://doi.org/10.1257/aer.89.3.473

Lo, G. S., \& Fall, A. M. (2011). Another look at second order condition in extreme value theory. Afrika Statistika. 6(1), 346-370.

Lo, G. S., Dème, E. (2012). A Functional Generalized Hill Process and Its Uniform Theory. International Journal of Statistics and Probability, 1(2), 250-268. https://doi.org/10.5539/ijsp.v1n2p250.

Marimoutou, V., Raggad, B., \& Trabelsi, A. (2009). Extreme value theory and value at risk: application to oil market. Energy Economics, 31(4), 519-530. https://doi.org/10.1016/j.eneco.2009.02.005

Mouridi, M., Hamidou, Joseph, K., Mung'atu, \& George, O. Orwa, (2018). Alternative Exchange Market Pressure Index Model for Currency Crisis. International Journal of Sciences: Basic and Applied Research(IJSBAR), 37(2), 186-215.

Ngom M., \& Lo, G. S. (2016). A Double-indexed Functional Hill Process and Applications. Journal of Mathematics Research, 8(4), 144-165. https://doi.org/10.5539/jmr.v8n4p144 URL: https://doi.org/10.5539/jmr.v8n4p144

Northrop, P. (2005). Semi-parametric estimation of the extremal index using block maxima. Preprint.

Ole Johan, A., Breivik, Ø., \& Reistad, M. (2012). Wave extremes in the northeast Atlantic. Journal of Climate, 25(5), 1529-1543, https://doi.org/10.1175/JCLI-D-11-00132.1

Persson, K., Stockholm, S., \& Ryden, J. (2010). Exponentiated Gumbel distribution for estimation of return levels of significant wave height.

Pozo, S., \& Amuedo-Dorantes, C. (2003, August). Statistical distributions and the identification of currency crises. Journal of International Money and Finance, 22(4), 591- 609. https://doi.org/10.1016/S0261-5606(03)00024-X

Qin, X., \& Liu, L. (2014). Extremes, return level and identification of currency crises. Economic Modelling, 37,439450.https://doi.org/10.1016/j.econmod.2013.11.035

Raynal-Villasenor, J. A. (2012). Maximum likelihood parameter estimators for the two populations Gev distribution. International Journal of Research and Reviews in Applied Sciences, 11(3), 350-357. 
Resnick, S. I. (1987). Extreme Values, Regular Variation and Point Processes. Springer - Verlag, New-York. (MR0900810)

Ribereau, P., Guillou, A., \& Naveau, P. (2008). Estimating return levels from maxima of non-stationary random sequences using the generalized pwm method. Nonlinear Processes in Geophysics, 15(6), 1033-1039.

Rocco, M. (2014). Extreme value theory in finance: A survey. Journal of Economic Surveys, 28(1), 82-108. https://doi.org/10.1111/j.1467-6419.2012.00744.x

Rootzn, H., \& Katz, R. W. (2013). Design Life Level: Quantifying risk in a changing climate, Water Resour. Res., 49, 5964-5972. https://doi.org/10.1002/wrcr.20425.

Rust, H. W., Kallache, M., Schellnhuber, H. J., Kropp, J. P. (2011). Confidence Intervals for Flood Return Level Estimates Assuming Long-Range Dependence. In: Kropp J., Schellnhuber HJ. (eds) In Extremis, 60-88. Springer, Berlin, Heidelberg. https://doi.org/10.1007/978-3-642-14863-7-3

Sachs, J., Tornell, A., \& Velasco, A. (1996, May). Financial crises in emerging markets: the lessons from 1995. National bureau of economic research Technical report No 5576, Brookings Papers on Economic Activity, 27(1), 147-199. https://doi.org/10.3386/w5576

Shajitha, S., \& Perera, K. (2014). Estimating return values of significant sea wave heights in colombo, sri lanka. Proceedings, 04th International Symposium, SEUSL: 469-473. http://ir.lib.seu.ac.lk/handle/123456789/1453

Smith, R. L. (1985, April). Maximum likelihood estimation in a class of non regular cases. Biometrika, 72(1), 67-90. https://doi.org/10.1093/biomet/72.1.67

Zhang, J. (2007). Likelihood moment estimation for the generalized Pareto distribution. Australian and New Zealand Journal of Statistics, 49(1), 69-77. https://doi.org/10.1111/j.1467-842X.2006.00464.x

\section{Copyrights}

Copyright for this article is retained by the author(s), with first publication rights granted to the journal.

This is an open-access article distributed under the terms and conditions of the Creative Commons Attribution license (http://creativecommons.org/licenses/by/4.0/). 